\title{
From The Calculus of Consent to extended logrolling, negative externalities, and the Coase theorem
}

\author{
Peter Bernholz
}

(C) Springer Science+Business Media, LLC 2012

My first exposure to some of the ideas analyzed in The Calculus of Consent took place in spring 1963. At that time, I participated in a seminar of Edward Banfield during the months I spent as a Rockefeller Fellow at Harvard University. Banfield, a well-known political scientist always open to new approaches, had invited three young scholars who worked at the forefront of what soon became known as public choice theory, namely Anthony Downs, Lieutenant Mancur Olson, and Gordon Tullock. We seminar participants where highly interested in their presentations, and on all three occasions a lively discussion arose. I had already used ideas of Downs's An Economic Theory of Democracy in my habilitation thesis on Aussenpolitik und internationale Wirtschaftsbeziehungen (Foreign Policy and International Economic Relations), but the subjects presented by Mancur Olson and Gordon Tullock were new to me.

No wonder that I soon read The Calculus of Consent. The book impressed me with the proof that different procedures for making political decisions recommended themselves, depending on the costs of decision-making for the problems to be solved compared to the disadvantages brought about by excluding members of society from the decision-making process. However, one of my early students, Malte Faber, now professor at Heidelberg University, found some problems with the result. He analyzed the question whether the assumption of unanimity at the constitutional level always prevented problems in establishing adequate decision rules at the operational level. He was able to show that in certain cases, especially when questions of income redistribution are at issue, the unanimity rule at the constitutional level leads to the establishment of the same rule at the operational level under plausible conditions. But this means that the approach used by Buchanan and Tullock is unable to explain income redistribution (Faber 1973).

For my own research, however, it turned out that quite by chance other ideas of the Calculus gained a bigger influence. When I began to work on my book Grundlagen der Politischen Ökonomie (Foundations of Political Economy) in the beginning of the 1970s,

P. Bernholz $(\bowtie)$

University of Basel, 4003 Basel, Switzerland

e-mail: Peter.Bernholz@unibas.ch 
Table 1 A logrolling example with two issues

\begin{tabular}{llll}
\hline & & \multicolumn{2}{l}{ Building a Theater } \\
\cline { 3 - 4 } & & yes & no \\
\hline Building a Football Stadium & yes & $2,2,-6$ & $\begin{array}{l}4,-3,-4 \\
\text { no }\end{array}$ \\
& no, & $-1,5,-2$ & 0,0 \\
\hline
\end{tabular}

I recalled the statement by Buchanan and Tullock that logrolling might provide certain protection of minorities: "Note that the results under logrolling and under non-logrolling differ only if the minority feels more intensely about an issue than the majority.... The above discussion suggests that a reasonably strong ethical case can be made for a certain amount of vote trading under majority rule" (Buchanan and Tullock 1962: 133f.).

Logrolling can be defined as meaning that one minority group supports the favorite project of another minority in exchange for their support of its own preferred project, though both do not like the project of the other. Because together they form a majority, they can succeed with their wishes by helping each other. For instance, if you support my wishes for building a theater I will support your plans for a football field. I thought that the idea of minority protection by Buchanan and Tullock was an appealing trait of logrolling and planned to insert an example of it into Grundlagen der Politischen Ökonomie. Thus I looked for a simple numerical example with a community comprising three voters like the following (see Table 1).

The figures represent the utilities of the three voters for each possible outcome of the vote(s). If the decisions on building a theater and a football stadium are taken separately and independently, both proposals will be rejected, because the first and the third voter are better off if no theater is built, and this independently of whether the stadium is voted for or against. And similarly, the second and the third voter form a majority against building the football stadium. But the outvoted minorities, namely the second and the first voter, respectively, have a chance to win if they strike an agreement to exchange votes in the sense that each of them does not vote only for his own but also for the other's aim. By doing so, they increase their utilities from 0 to 2 . But as a consequence the third voter faces his worst outcome with a utility of -6 .

So far, so good. Unfortunately I quickly found out that the (yes, yes) outcome is not stable. For the third voter could offer the second voter a vote for the theater in exchange for a vote against constructing the stadium. Under this exchange, his utility rises from -6 to -2 , whereas that of the second voter increases from 2 to 5 . Alternatively, he could offer to support voter 1's bid for the stadium in exchange for a vote against the theater, an outcome that would be better for both of them. But that is still not the end of the story. Compared to the asymmetric outcomes in which only one building is funded, the outcome (no, no) is better for a coalition of the first and third voters, or for a coalition of the second and third voters, respectively. We thus get two cycles of "social preferences":

(1) $($ yes, yes $)>($ no, no $)>($ yes, no $)>$ (yes, yes $)$ and

(2) $($ yes, yes $)>($ no, no $)>($ no, yes $)>$ (yes, yes $)$.

"Bad luck," I thought when I saw this result. "By chance, I must just have taken some unfortunate numbers for the utilities to produce this cycle." So I looked for other numbers. But again the same result occurred, and the same for another example. Then the idea dawned on me that this might be not by chance but rather a universal result. But how to prove it? I had no solution. However, my subconscious mind worked on the problem. For when I took a walk in the snow a few weeks later in Grächen in the mountains of the Valais, where our 
Table 2 General case of logrolling with two issues

\begin{tabular}{llll}
\hline & & Issue One & \\
\cline { 3 - 3 } & & yes & no \\
\hline Issue Two & yes & $\mathrm{a} 1, \mathrm{~b} 1, \mathrm{c} 1$ & $\mathrm{a} 2, \mathrm{~b} 2, \mathrm{c} 2$ \\
& no & $\mathrm{a} 3, \mathrm{~b} 3, \mathrm{c} 3$ & $\mathrm{a} 4, \mathrm{~b} 4, \mathrm{c} 4$ \\
\hline
\end{tabular}

daughters were skiing, I suddenly had an epiphany about how to solve the problem with simple mathematics. Let me sketch the proof here (Table 2) for two issues, each with two alternatives, similar to the numerical example of Table 1, but now generalized.

To make logrolling possible, that is, profitable for two voters, we have to make certain assumptions concerning their preferences, where $\mathrm{P}$ means preferred:

First voter: $\quad$ a3 $\mathrm{P}$ a1 $\mathrm{P}$ a4 $\mathrm{P}$ a2

Second voter: $\quad$ b2 $\mathrm{P}$ b1 P b4 P b3

Third voter: $\quad$ c4 P c2 P c3 P c1

In this case it is profitable for the first and the second voter to form a logrolling coalition. It is easy to see that also in this general case relations (1) and (2) hold. This means that whenever we have a logrolling situation for two issues with two alternatives, cyclical social preferences result. This would not change if the logrolling possibilities involved voters 1 and 2 or voters 2 and 3 instead of for voters 1 and 3 .

At this point it seems appropriate to explain briefly what I mean by "cyclical social preferences." I do not accept the idea that there exist social preferences of a community or political body comparable to individual preference orderings. Consequently for me cyclical social preferences just mean that the decisions of a collective body may lead to inconsistent or contradictory outcomes. This could also mean that the sequence of voting on different alternatives can be manipulated by a chairman controlling the agenda. Or the result may be a chance event depending on which pairs of alternatives are voted on in which sequence. And finally, when all possibilities are voted on in the sequence of time, the former results may be overturned.

My paper containing the proof of this theorem appeared in Public Choice (Bernholz 1973) but was still limited to two issues. In spring 1974, my family and I accepted an invitation from the Center for Study of Public Choice at the Virginia Polytechnic Institute to spend a sabbatical semester in Blacksburg. Buchanan and Tullock insisted that I should join them for the meeting of the Public Choice Society at Yale University in New Haven soon after our arrival. At the conference, I attended a session of interest to me and was much surprised when one of the speakers referred to my paper as an important contribution, only regretting that it was still limited to the case of two issues each with two alternatives. I was able to report that I had worked out a generalization to $n$ issues each with $m_{n}$ alternatives $\left(n, m_{n} \geq 2\right)$ which had just appeared in Kyklos (Bernholz 1974).

The problems related to logrolling have never quite left me since that time and have led to a series of publications over more than two decades. Already at my first stay in Blacksburg I received letters from a philosopher, Thomas Schwartz, in which he doubted my results and tried to disprove them by providing counter-examples. In the following exchange of letters I could convince him that his examples referred only to minority coalitions not bringing together majorities of voters. After that he became an ardent adherent of the theory and contributed to its further development. He soon published an article (Schwartz 1977) in which he generalized my results to all other non-dictatorial decision rules, whereas I had only analyzed qualified majority voting up to near-unanimity besides simple majority voting. 
Table 3 Reading Lady

Chatterley's Lover

\begin{tabular}{llll}
\hline & & Daughter & \\
\cline { 3 - 4 } & & Read & Do not read \\
\hline \multirow{2}{*}{ Mother } & Read & a1, b1 & a2, b2 \\
& Do not read & a3, b3 & a4, b4 \\
\hline
\end{tabular}

Thus his approach also considered other decision rules, including liberalism, i.e., the case in which issues are decided by different individuals. However, his proof was limited to the case of separable individual preferences, and his paper also did not make it clear what kinds of assignments of decision rights were incorporated and what this generalized logrolling theorem meant for the corresponding social organization. Subsequently I was able to remove these gaps (Bernholz 1980; similar results were presented independently by Schwartz 1981; see also Schwartz 1986), and also to show that the assumptions and results implied a substantive interpretation of Arrow's (1963) impossibility result for a finite number of two or more issues.

The main lines of the further development of my work in this field can best be understood after mentioning two facts. First, logrolling between two or more parties means nothing else than a contract to decide issues (in the above example: to vote) in a certain way. Second, the person(s) outvoted experience a negative externality because of the votes of the others. Thus, it is not surprising that I could show (Bernholz 1982) that cyclicality is present only if negative external effects including the negative effects on outvoted people are present. The latter idea of "politically" caused negative externalities was again an idea already expressed in The Calculus of Consent (pp. 60ff.).

Now, if the decisive factors causing cyclical social preferences are (a) contracts favoring participants, and (b) negative externalities, then it is not surprising that the "logrolling" results could be extended by Schwartz and myself to all other contracts. After all, contracts are agreed to only if they secure better results for the participants. A simple example showing this is provided by the so-called paradox of liberalism put forward by Amartya Sen (1970), presented in Table 3 according to my interpretation. The preferences for daughter and mother are as follows:

\section{Daughter: a1 P a2 $\mathrm{P}$ a3 $\mathrm{P}$ a4 \\ Mother: $\quad$ b4 P b2 P b3 P b1}

The mother prefers most that both she and her daughter do not read the somewhat lascivious book. As the next best outcome she prefers that she rather than her daughter reads it. Next in her preferences is the case that her daughter but not she reads the book. The worst case for her is if both of them would read the book. The daughter's preferences favor most the case in which both read the book and the worst if nobody reads it. But she rather prefers that her mother alone read it than only she herself does. Obviously she wants to educate her mother to a more liberal attitude.

Now assume that both have the right to decide whether they themselves read the book or not. In this case the result would be that the daughter but not the mother reads the story. But this is not Pareto-optimal, since they would prefer a 2 to a3 and b2 to b3, respectively. As a consequence Sen calls this the Dilemma of a Paretian Liberal, since both mother and daughter have the liberal right to decide their own affairs. However, in a true liberal society the two should also have the right to improve their position by concluding a contract. But if they agree to a contract since it makes them both better off, the Pareto-optimal outcome (a2, b2) would result. But unfortunately again, cyclical social preferences result, if either 
the daughter or the mother does not honor the contract, similar to the logrolling case. For, the daughter could read the story because this would lead to a better position for her. And then the mother could also change her behavior, and so on. Thus, a cycle results. The same would be the consequence if the mother would first break the contract.

In this example, the negative externality arises because mother and daughter have the liberal right to decide for themselves on their own behavior, and not from being outvoted as in the example in which a group has the right to take decisions, for instance by majority voting. It follows that the problems of cyclical social preferences arise for two reasons: first, the assignment of rights to different individuals or groups to decide issues and, second, because in taking those decisions certain rules like majority or unanimity voting, a chance mechanism, voting by an oligarchy or dictatorship are valid. Note that such decision rules may also imply or deny rights for members of society.

It should not be surprising that further work started from the assignment of rights to the members of society and from the decision rules used. My thinking thus followed in a way the path taken by Buchanan and Tullock in the Calculus. As mentioned above, I had shown that for the case of two or more issues, each with at least two alternatives, the results implied a substantive interpretation of Arrow's Impossibility Theorem, the theorem taken as meaning that no non-dictatorial transitive social preference function existed if all possible different profiles of individual preference functions were considered. Here the expression "profile of individual preference functions" refers to the set of the preferences of all individuals in a society. But then Arrow's approach can be seen as follows: Namely that his analysis starts from any assignment of rights and decision rules taken as a parameter, and that he proved starting from this assumption that there existed always at least one combination of the preferences of all members of society in which intransitive, that is cyclical social preferences, resulted. Arrow thus took the profiles of individual preferences as a variable.

Having realized this, I thought: "Let's turn this way of looking at things upside down: Let's start from any profile of individual preferences taken as a parameter and examine whether there always exists at least one assignment of rights to take decisions, and of decision rules, preventing cyclical social preferences." If this were the case, the Arrow Paradox could always be solved or prevented by an adequate assignment of rights, decision rules, or both. Fortunately, my analysis was successful and I was able to provide the proof for the most general case (Bernholz 1986). Here I will just illustrate the result for the cases of Tables 2 and 3. First, consider the following change of assignment of rights in Table 3: The mother now has the right to decide whether the daughter should read or not Lady Chatterley's Lover, whereas the daughter gets the right to decide on the reading of the mother. In this case the Pareto-optimal outcome with a 2 and b2 would result.

In Table 2 let us consider first the introduction of the unanimity rule of voting. In this case the result with 'no' for both issues and utilities a4, b4, c4 is the Pareto-optimal outcome. Again no cycle is present. Another case would be to assign decision rights only to an oligarchy of the first and the second individuals who decide by majority voting (here equal to unanimity). In this case both issues will be decided with a 'yes' and utilities a1, a2, a3 result. The outcome is again Pareto-optimal.

The proof for the general constitutional possibility theorem given in my paper quoted above has led to two important additional insights. First, there exists always one purely liberal assignment of rights (in which case only different individuals have the right to decide issues) allowing Pareto-optimal outcomes and preventing cycles. However, if the number of issues is smaller than the number of individuals this would imply a kind of oligarchic pure liberalism. Second, an assignment of the rights to decide all issues to all members of society by using simple majority voting does not allow a Pareto-optimal solution without cyclical social preferences. 
It has been argued (and also been evident to me) that in reality the constitutional assignment of rights to take decisions and of decision rules to prevent Arrow's Paradox would require the knowledge of the preference orderings of all individuals. In this sense the constitutional approach taken in my paper was certainly problematic. Thus I tried to find another solution which started from the realization that the problems leading to cyclical social preferences possibly including Pareto-optimal and Pareto-inferior outcomes with two or more issues were caused by contracts between several parties. I also recalled that according to the Coase Theorem the problem of negative externalities could be solved by agreements among the parties concerned, independently of the assignment of property rights provided that no transaction costs were present. Moreover, my constitutional approach had shown that there always exist assignments of rights and non-dictatorial decision rules leading to Paretooptimal outcomes and preventing cyclical social preferences. Given these insights, should it not be possible to reach such outcomes by stepwise bargaining among parties interested in improving their present positions? Unfortunately the problem proved to be difficult, especially since Aivazian and Callen (1981) had shown that the Coase Theorem is no longer valid if more than two parties are involved.

So it took several years until I was able to solve the problem in the form of a general mathematical proof. I finally succeeded in generalizing the Coase Theorem by introducing the postulate of binding contracts. For if contracts were binding so that they could not be broken it was possible to show that by a process of bargaining, moving possibly from contract to contract, it was always possible to reach a stable Pareto-optimal outcome, so that no cyclical social preferences remained (Bernholz 1997, 1999). The proof also implies the irrelevance of Arrow's Impossibility Theorem and of Sen's theorem of the Impossibility of a Paretion Liberal under the conditions stated. For the examples of Tables 1, 2, 3 the validity of the theorem can be easily shown, since only one contract is involved in these simple cases.

If the contract between mother and daughter in Table 3 is binding it cannot be broken. Consequently the cycles are suppressed and the stable Pareto-optimal outcome results. Similarly, if in the examples of Tables 1 and 2 the contract between voters 1 and 2 is binding, no further agreements between voters 1 and 3 or voters 2 and 3 can be concluded, for such agreements would lead to a violation of the contract by either voter 1 or voter 2 , which is not permitted if it is binding. In reality, of course, it depends on the severity of the sanctions following a breach of a contract whether it is indeed binding under all circumstances. But the result demonstrates the importance of legal systems and of social pressures enforcing the validity of contracts for the optimal working of societal processes.

The general proof of the theorem is, of course, rather complicated (for a relatively simple discussion see Mueller 2009: 32-34). In fact, contracts including up to $n$-issues may be necessary to get stable Pareto-optimal outcomes. And this implies that transaction costs can no longer be neglected because they generally will be greater the more issues and people are involved. Indeed, this may have been an important historical reason for the development of organizations (including political bodies and states). Or as Buchanan and Tullock (1962: 48) expressed it in the Calculus: "We shall argue that, if the costs of organizing decisions voluntarily should be zero, all externalities would be eliminated by voluntary private behavior of individuals regardless of the initial structure of property rights.... The choice between voluntary action, individual or cooperative, and political action, which must be collective, rests on the relative costs of organizing decisions...".

The first sentence obviously refers to the Coase Theorem, and has not been proved by the authors, but only in my papers mentioned above. However, their statement certainly opened the right way of pursuit. My proof has the additional advantage of revealing that two more 
assumptions had to be introduced to generalize the Coase Theorem: First, if weak individual preference orderings are present, that is, if individuals are indifferent among certain outcomes, at least one issue has to refer to a good which is finely divisible and valued positively by all members of society. Second, if non-separable individual preference orderings are present, it is necessary that the contract(s) include(s) several Pareto-optimal outcomes occurring after each other with certain frequencies. This result implies that the partners concluding the contract have to be guaranteed that their most preferred Pareto-optimal outcome will favor them with a given regularity. Thus a distribution of benefits among the partners is taken into account in the contract.

It is interesting to note that binding contracts are especially missing in the sphere of politics. This means that stability is present only in repetitive games played, for instance, in parliaments like the US Senate, where members remain in office with a certain probability as potential participants in future agreements (Bernholz 1978). But in this field, too, interesting scientific developments have taken place during the last years. My former student, Hans Gersbach of ETH Zürich, has developed several approaches to how politicians could be bound by binding contracts leading to better political results (Gersbach 2005, 2008).

\section{References}

Aivazian, V. A., \& Callen, J. L. (1981). The Coase theorem and the empty core. The Journal of Law and Economics, 24, 175-181.

Arrow, K. J. (1963). Social choice and individual values. New York: Wiley.

Bernholz, P. (1973). Logrolling, arrow-paradox and cyclical majorities. Public Choice, 15, 87-95.

Bernholz, P. (1974). Logrolling, arrow-paradox and decision rules: a generalization. Kyklos, 27, 49-72.

Bernholz, P. (1978). On the stability of logrolling outcomes in stochastic games. Public Choice, 33, 66-82.

Bernholz, P. (1980). A general social dilemma: profitable exchange and intransitive group preferences. Zeitschrift für Nationalökonomie, 40, 1-23

Bernholz, P. (1982). Externalities as a necessary condition for cyclical social preferences. Quarterly Journal of Economics, 47, 699-705.

Bernholz, P. (1986). A general constitutional possibility theorem. Public Choice, 51, 249-265.

Bernholz, P. (1997). Property rights, contracts, cyclical social preferences and the Coase theorem: a synthesis. European Journal of Political Economy, 13, 419-442.

Bernholz, P. (1999). The generalized Coase theorem and separable individual preferences: an extension. European Journal of Political Economy, 15, 331-335.

Buchanan, J. M., \& Tullock, G. (1962). The calculus of consent. Ann Arbor: University of Michigan Press.

Faber, M. (1973). Einstimmigkeitsregel und Einkommensumverteilung. Kyklos, 26, 36-57.

Gersbach, H. (2005). Designing democracy: ideas for better rules. Heidelberg: Springer.

Gersbach, H. (2008). Contractual democracy. CEPR Discussion Paper No. 6736.

Mueller, D. (2009). Public choice III. Cambridge: Cambridge University Press.

Schwartz, T. (1977). Collective choice, separation of issues and vote trading. American Political Science Review, 71, 999-1010.

Schwartz, T. (1981). The universal instability theorem. Public Choice, 37, 487-501.

Schwartz, T. (1986). The logic of collective choice. New York: Columbia University Press.

Sen, A. K. (1970). The impossibility of a Paretian liberal. Journal of Political Economy, 78, 153-157. 